\title{
Discapacidad intelectual
}

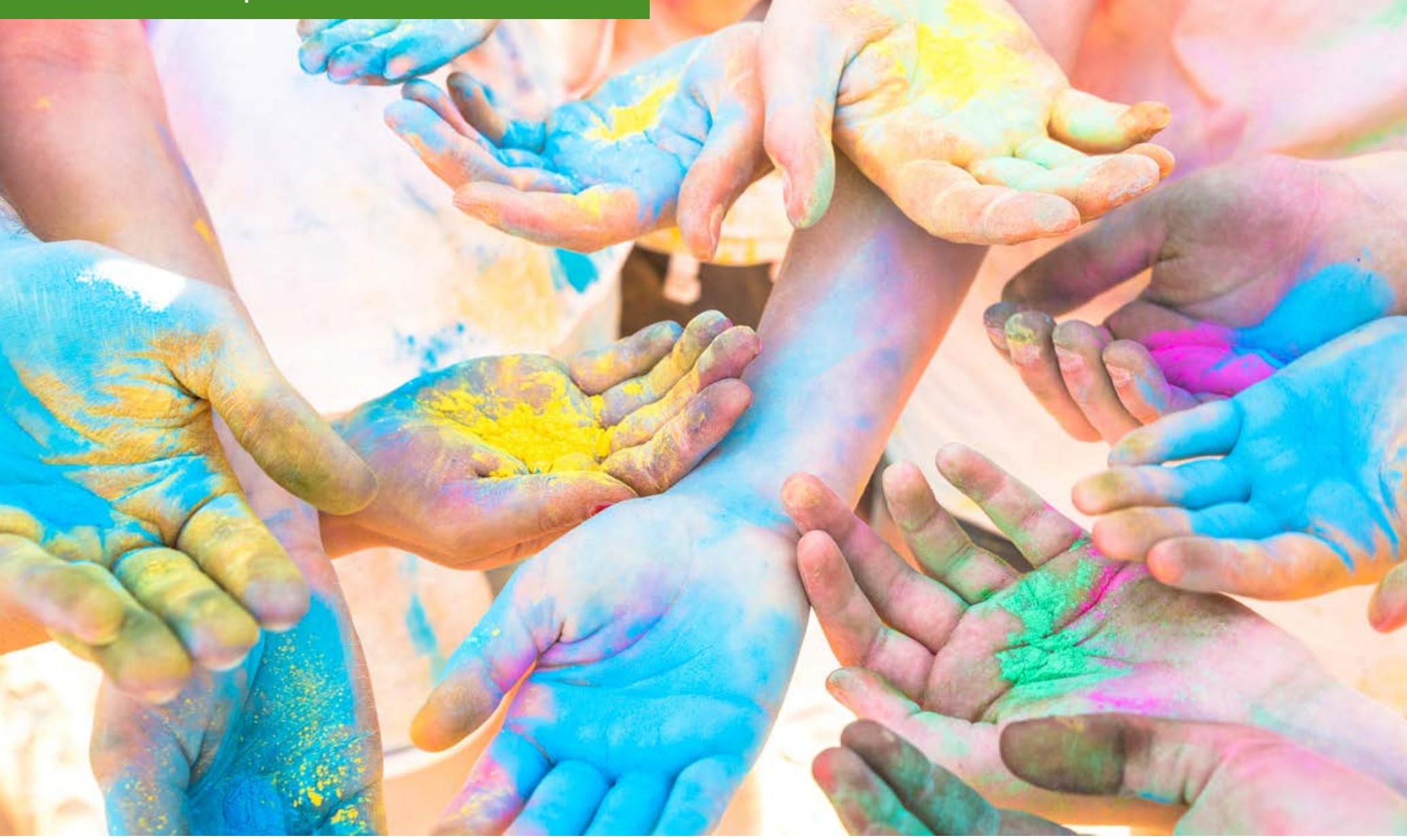

\section{Discapacidad intelectual: aportes de la bioética al modelo social en educación inclusiva}

Intellectual Disability: The Contributions of Bioethics to the Social Model in Inclusive Education

(2) Autores

María Martha Fernández

Cátedra de Pedagogía Impolítica -

Fundación Diides

E-mail: mariamarthafernandez@gmail.com

(iD) https://orcid.org/0000-0001-7093-9978
Alberto Vivas Peralta

Institución Fundación Maestros Azules

licvivasperalta@gmail.com 
Resumen

Abstract

Key words

Bioética; discapacidad intelectual; ética inclusiva; educación inclusiva.

Bioethics; intellectual disability; inclusive ethics; inclusive education.

Recibido: 18/11/2020. Aceptado: 23/01/2021
Este artículo reflexiona sobre el horizonte del modelo social al pensar la inclusión educativa desde una ética que atienda a la diversidad, a los derechos que garanticen la no violencia, la dignidad y el respeto, observando la alteridad interpelada desde la discapacidad intelectual. Pensar un ethos inclusivo y los aportes que puede compartir con la bioética, para agotar el paradigma de déficit que sigue impidiendo la mirada abierta al Otro levinasiano para una educación inclusiva.

This article reflects on the limits of the social model when we think of educational inclusion from the perspective of ethics related to diversity, of rights that guarantee non-violence, dignity and respect, considering the assumed otherness of intellectual disability. We reflect on an inclusive ethos and the contributions that may be shared with Bioethics, in order to eliminate the idea of "deficit" that continues to prevent an open look at the Levinasian concept of Otherness for an inclusive education. 


\section{Introducción}

Pensar una educación inclusiva como un modelo superador, generar una matriz conceptual para una pedagogía de las diferencias, que en nuestros tiempos están atravesadas por la crisis económica, social y ambiental, desde una ética inclusiva. Para ello basta tomar la educación especial la que, como oferta escolar, ancla en modelos caducos ${ }^{1}$ como lo es el caso de las personas con discapacidad, concibien-

El espacio escolar no admite escisiones provenientes de pensamientos polarizados, invisibilizando posibilidades intermedias

do la educación como un proceso de homogeneización o normalización cultural, social e identitaria, sin considerar la diversidad que supone nuestra sociedad contemporánea. Comprender que un espacio escolar es inexorablemente un espacio de reproducción, por lo que la diversidad es una experiencia vivida-aprendida en ese espacio de convivencia. Estas visiones siguen varadas incluso en los institutos de formación docente y en carreras de grado, posponiendo una inmersión urgente del modelo social, a la hora de formar profesionales de la educación con los recursos necesarios para generar espacios de transformación de la realidad, con capacidad crítica ${ }^{2}$ y dinámica creativa, en alas del ejercicio de los derechos humanos, sin reducción ni violencias y siempre garantizando espacios de dignidad y equidad para todos los participantes de la experiencia educativa, donde las relaciones sociales, éticas, históricas y políticas puedan darse sin caer en los lineamientos liberales de necesidad y eficiencia, permitiendo patrones de control como observan desde la pedagogía crítica, lo que supondría un cambio profundo del proyecto político de Iberoamérica ${ }^{3}$.

La violencia que supone la precarización y vulneración de la diversidad, en tensión con la visión de la Educación Especial que debe cuestionarse, ante lo que en sus multidimensiones: lingüística, de género y cultural supone, la diversidad funcional ${ }^{4}$ es la más vulnerada, y en ella nos detendremos, ya que la discapacidad se impone como el factor más complejo a la hora de realizar ajustes de raíz. El espacio escolar no admite escisiones provenientes de pensamientos polarizados, invisibilizando posibilidades intermedias:

La definición de la identidad de una persona se establece entre la naturaleza y la tecnología, lo masculino y lo femenino, el negro y el blanco, en los espacios que

1 Los que incluyen la educación especial y el modelo de integración.

2 Pensando lo crítico en el sentido de transformador y no conformista, por tanto, activo-creativo.

3 Se considera Iberoamérica por compartir una matriz simbólica lingüística y cultural, lo que no supone una homogeneización de imaginarios revelados, gracias a las epistemologías emergentes decoloniales, sino un conjunto de identidades simbólicas que buscan "decirse" con voz propia.

4 La diversidad se observa desde las normalidades diferenciales y fragmentarias, que intentan superar las definiciones en negativo (discapacidad, minusvalía, invalidez), reclamando el derecho al pleno reconocimiento de su dignidad, como una expresión de las pluralidades que, en la actualidad, son reconocidas positivamente en nuestra convivencia colectiva. La diversidad funcional contemplada también como una cuestión de derechos humanos, civiles, políticos, culturales y económicos. Esta denominación será la escogida por la necesidad de comprender a la persona en un entramado multidimensional y diverso, en convivencia y aprendizaje con la diferencia. Ainscow sobre la inclusión y la diferencia: "de este modo la diferencia es un factor más positivo y un estímulo para el aprendizaje de menores y adultos" (2003, p. 12). 
fluyen y que generan conexiones entre dichas categorizaciones. Vivimos en un constante proceso de transición, de hibridación y de nomadización, y estos estados y etapas intermedias desafían los modos establecidos de representación teórica. (Braidotti, 2005, p. 15)

Asimismo, Yarza de los Ríos (2013) ${ }^{5}$ advierte un punto muy pertinente, que supone la reducción semántica y política a lo vulnerable, ya que de esta manera respondería a la visión de diversidad estigmatizada y dependiente de la caridad, productos de trayectorias históricas de olvido, precarización y violencia que se documenta en torno a las enfermedades mentales y a la discapacidad funcional.

En la diversidad, un extremo Otro que no es escuchado, que quizás no puede enunciarse por sí mismo y que requiere ajustes, es el de las personas con discapacidad intelectual. En el ámbito educativo, la educación especial ha sido, también, un extremo Otro habitado por los que no en-cajan en el espacio escolar. Estas alteridades límites confrontan modelos establecidos, que sobreviven desde una mirada médica,

En el ámbito educativo, la educación especial ha sido,

también, un extremo Otro

habitado por los que no

en-cajan en el espacio escolar con un modelo en el que la persona sea observada no desde el déficit, sino a partir del ejercicio de derechos, la autonomía y, sobre todo, como un actor social que puede representarse por sí mismo, con los ajustes necesarios o con el acompañamiento de la familia o el Estado ${ }^{6}$. Enríquez Canto busca contribuir con el aporte de Lévinas, sin que este sea único y definitivo, pero que ahonda en la relación, como apertura a la alteridad, que supone la discapacidad cognitiva y un espacio educativo considerando la discapacidad intelectual a la "caracterizada por limitaciones significativas, sea en el funcionamiento intelectual o en el comportamiento adaptativo, que se expresan mediante habilidades conceptuales, sociales y prácticas (Schalock et al., 2010)" (Enríquez Cantó, 2018, p. 232), lo que diferencia la discapacidad intelectual de la cognitiva, siendo esta más amplia.

\section{Lo que la discapacidad cuestiona}

Al problematizar la educación inclusiva, se pondera la interseccionalidad de la diversidad en todos sus aspectos, ya que responden a las diferencias que habitan los espacios educativos. Desde esta propuesta ético-política, desterramos la posibilidad de un

5 Yarza de los Ríos, V. A. (2013). Hacer sitio al que llega: pedagogía, educación especial y formación. Contextos de Educación, 14, 36-43. "Al viajar hacia otras formas de lo otro, sin reducirlo semántica y políticamente a lo vulnerable, pluralizamos la mirada y los pensamientos sobre la inclusión (además de otros asuntos y fenómenos de la sociedad y lo humano en un sentido heterogéneo), pero también corremos el riesgo de generar una disolución peligrosa mediante nuestra indistinción que borraría, precisamente, las diferencias" (p. 37).

6 Somos conscientes del papel de la familia en la discapacidad en caso de que esta estuviese presente, pero en muchos países estas personas quedan en manos del Estado o, en su ausencia, de entidades privadas. 
reversionamiento de la escuela especial, ya que, en coincidencia con Yarza de los Ríos, se trata de un ejercicio que:

[...] interpela esa grandilocuente inclusión que pertenece y está dirigida a un supuesto "todos", pero que son delimitados por la etiqueta de vulnerables, dejando por fuera los que no son categorizados ni distinguidos por el atributo de lo vulnerable: es decir los "no vulnerables". Por tanto, la inclusión no es para todos o, por lo menos, quedaría la pregunta abierta: ¿quién hace parte de ese todos?. (Yarza de los Ríos, 2013, p. 38)

En esta urdimbre que conforma matrices conceptuales discursivas y dimensiones simbólicas, el enfoque antropológico revela el concepto de "mácula", tal y como sucede con las enfermedades que exponen la posibilidad de nuestra finitud, al rechazo por el contagio ilógico de supervivencia. Pérez de Lara ${ }^{8}$ indica que la imagen del deficiente interroga a la "normalidad", como el loco a la "razón" y los niños

“La discapacidad intelectual
tiene la potencialidad
de cuestionar el modelo
idealizado del sujeto racional,
independiente y autónomo que
de frecuente es empleado al
escribir lo humano"
(Enríquez Canto)
a "la madurez", en consonancia con el enfoque bioético en el que "La discapacidad intelectual tiene la potencialidad de cuestionar el modelo idealizado del sujeto racional, independiente y autónomo que de frecuente es empleado al escribir lo humano" (Enríquez Canto, 2018, p. 239).

Bajo esta óptica, diferentes momentos generaron la coyuntura para que tres modelos emerjan, describe Palacios (2008), en una evolución histórica. El modelo de prescindencia que expresaba un imaginario mágico-religioso, en el que la discapacidad es justificada desde cuestiones religiosas, y la persona con discapacidad era una carga, ya que la vara era la producción, por lo que la marginación provocó la "prescindencia" de sus vidas. Esta instancia se resolvía con infanticidios, mendicidad y la exposición, muchas veces, como "fenómenos de feria" plasmados en el personaje del Quasimodo". Desde el imaginario mágico, lograban explicar uniones malditas, circunstancias cósmicas o metafísicas que provocaban anomalías, muertes súbitas o enfermedades. Esto se legitima posteriormente con la religión que colabora en la legitimación de la primacía de la ciencia en la modernidad que impone el progreso, y la producción que contextualiza el modelo rehabilitador, justificando que las personas con discapacidad, al no producir, deben ser normalizadas por las instituciones.

7 La mácula, como la marca de enfermedad, de distinción o muerte, “En la muerte, según vimos, los símbolos tradicionales tienden a endurecer a los individuos frente a la pérdida social y también a recordarles sus diferencias". Geertz, C. (2003). La interpretación de las culturas. Barcelona: Editorial Gedisa, p. 149-150.

8 En Marchant Fernández, C. (2009). La voz del alumnado de la educación especial proveniente de la educación ordinaria. Historias de vida y exclusión educativa en Barcelona (Tesis Doctoral). Universitat de Barcelona, Barcelona.

9 Quasi-modo, "casi”, demuestra la focalización de la época que impacta en este modelo en la falta, carencia, deficiencia. La versión literaria y posterior cinematográfica describe a un niño abandonado en la Catedral de Notre Dame que vive oculto hasta que es descubierto por el amor. El amor, ¿erótico o compasivo? 
Desde la dimensión simbólica, la teoría interaccionista de Goffman ${ }^{10}$ propone la visión de la interacción social negativa, representada en una condición personal devaluada frente a la sociedad. El estigma de una identidad deteriorada explica su inferioridad y el descrédito que opera en la objetivación y la posterior invisibilización.

Otras visiones emergen. En el ámbito institucional, Oliver (1996) propone revocar el minusvalismo institucional, resultado del fracaso del entorno social, en tanto que se considera al colectivo con discapacidad como ciudadanos con carencias. Al mencionar ciudadano se presupone un gran logro: un sujeto de derechos dentro de un marco legalpolítico de Estado.

El modelo social, horizonte actual que estamos transitando y transicionando, supone que la exclusión social es provocada por barreras sociales. Instala una visión que contrargumenta las posiciones individualistas y propias de la anatomopolítica ${ }^{11}$ que imperó hasta el siglo XVII-XVIII, que concebían al hombre/cuerpo y los atendían con instituciones asistencialistas muchas veces dependientes, ya sea directa o indirec-

Las contribuciones de Foucault permiten indagar sobre la

perpetuación y superposición de los modelos sobre la

discapacidad, así como la moral religiosa, que siguen marcando su impronta en nuestros días tamente, de la Iglesia. Foucault propone otra mirada, observando el recorrido histórico en la visión de los cuerpos y lo disciplinar, comprendiendo el biopoder como políticas de la vida biológica, entre ellas las políticas de la sexualidad, y como poder sobre la muerte, cuestiones con las que este ha operado el capitalismo. La tecnología disciplinaria pasó a centrarse en la seguridad -según este filósofo, en los siglos XVIII y XIX- del cuerpo individual hacia la especie y a la biopolítica con un sesgo masivo, colectivo. En este encuadre histórico-social, la ciencia tiene el papel de disminuir la mortalidad, alargar la vida, estimular la natalidad, para lo cual la enfermedad supone una sustracción de fuerzas, disminución del tiempo de trabajo, reducción de las energías, costos económicos. El nuevo funcionamiento de la medicina y de la higiene como saber/poder intentarán intervenir sobre los procesos biológicos y orgánicos del cuerpo y la población.

El dispositivo disciplinar y normativo ha atravesado los modelos, la visión y la relación institucional con el Estado, excluyendo las diferencias. Las contribuciones de Foucault permiten indagar sobre la perpetuación y superposición de los modelos sobre la discapacidad, así como la moral religiosa, que siguen marcando su impronta en nuestros días. De igual manera, la hegemonía médica se encuentra legitimada por el Estado, ya que es la comunidad médica la que dispone sobre las personas, en ámbitos donde carecen de experticia, como es el de la educación ${ }^{12}$. Los procesos socioculturales atravesados por los dispositivos de poder, seguridad, salud, cuyos tiempos de emergencia son más prolongados, y más allá de que los modelos puedan identificarse, podemos asegurar que hoy estamos en una etapa transicional hacia una

10 Goffman, E. (2006) Estigma. Buenos Aires: Amorrortu.

11 Desde la visión foucaultiana sobre la tecnología disciplinaria de la anatomopolítica del cuerpo humano.

12 En Argentina, en la obtención del certificado único de discapacidad (CUD), la categorización proviene del ámbito médico-psicológico. Es el pediatra el que debe solicitar el apoyo pedagógico o psicopedagógico, para los ajustes en educación. 
fuerte intención de todos los actores a habitar el modelo social, que está fuertemente influida por la crisis institucional agravada por la pandemia, en la que se verifica que la principal exclusión es determinada por la accesibilidad a la comunicación y a la movilidad $^{13}$.

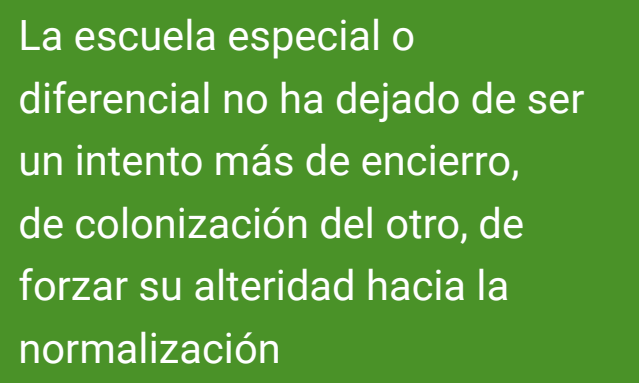

La dificultad que en este momento se sortea ante la diversidad es la medicalización de la vida, la que contribuye al monopolio médico que rehabilita, restituye ubicando a las personas como pacientes ${ }^{14}$ y se articula con la intervención judicial. En cuanto a la ley, a partir de la década de los 40 surgen nuevos derechos, promoviendo una nueva moral que habilita la intervención del Estado.

Ante la necesidad de explicar las invisibilizaciones de colectivos y prácticas excluyentes que ocultan tabúes, la convivencia de los modelos desplazándose, superponiéndose o presentando diferentes intensidades, operan justificando las exclusiones, con argumentaciones que siguen resonando y perduran en las matrices simbólicas, que hasta el día de hoy se encuentran camufladas en pseudomorales, no morales.

El modelo social alienta a la lectura social del cuerpo como construcción social de identidad, debiendo estar anclada históricamente y, volviendo a Foucault, no velando la subjetividad del cuerpo por las necesidades de progreso, producción y rendimiento. Para que la construcción social sea posible, las matrices simbólicas deben ser coherentes. Es ahí la exigencia y urgencia de un ethos que habilite la expresión y acción en alerta permanente, como lo indica Lévinas, con una actitud vigilante hacia el cuidado del Otro.

\section{Normalidad y diversidad, integración e inclusión}

En la dimensión simbólica se sigue sosteniendo la normalidad y sanidad, como un significante habitado por el discurso médico. En cuanto a la escuela especial o diferencial, no ha dejado de ser un intento más de encierro, de colonización del otro, de forzar su alteridad hacia la normalización. Aquí, cabría el interrogante de si solo es la escuela especial la que intenta colonizar en un desesperado pequeño encierro, siendo que es la escuela convencional la que parece profundamente presionada por la necesidad de

13 Considerando que estamos atravesando la pandemia y no se pueden exponer conclusiones, se presentó Democracia Viva, donde participaron referentes de Latinoamérica, y el II Encuentro Virtual de Profesionales en Red por la accesibilidad: Discapacidad y accesibilidad en tiempos de Crisis y Pandemia. Se destaca que la exclusión surge de la falta de accesibilidad o la falta de conectividad, lo que impacta en el acompañamiento con adecuaciones curriculares y de atención en las trayectorias escolares, en todos los niveles educativos.

14 Sin ánimo de profundizar en la instauración e impacto de la consideración "paciente", destacar que esta connotación borra características particulares. Es importante el aporte que se recoja en la educación hospitalaria sobre esta puja que se configura entre el ser paciente y ser estudiante. 
controlar, ordenar y vigilar la creciente población educativa ${ }^{15}$. El discurso normalizador no afecta solo a las personas con deficiencia, sino que regula también las vidas de las personas consideradas normales. Deficiencia y normalidad forman parte de un mismo sistema.

La escuela especial no deja de ser un intento más de reduccionismo, al pensarlo en términos de inclusión/exclusión.

Los modelos sociales cuentan con su contraparte, por concepción y concordancia histórica. En principio la educación especial ${ }^{16}$ respondería a una visión segregadora y daría asistencia médica, psicológica y terapéutica para tratar los déficits con personal especializado, para los rotulados deficientes y anormales (Arnaíz, Berrue-

En los años 40, y ante los

derechos reclamados por

las propias familias, surge

el modelo integrador que

promueve la adquisición de

habilidades zo, \& Illán, 1998). Las instituciones de encierro-internación, por un lado, y la escuela, por el otro, fueron soportes desplegados institucionalmente. El aumento de niños "débiles mentales", obligaba a la creación de centros de atención con especificidad según la discapacidad, donde lo médico y lo educativo tenían su hibridaje. La educación especial se fundamenta sobre estas bases, hasta nuestros días. A partir del siglo XX, la educación especial basó sus fundamentos en los aportes de la psicología y la pedagogía, incluyendo equipos de educadores, psicólogos y médicos, centrados en el sujeto deficiente, con el espíritu de revertir la patología. Este proceso carece de un horizonte social a raíz de sus prácticas terapéuticas que objetivan des-subjetivando. En los años 40 , y ante los derechos reclamados por las propias familias, surge el modelo integrador que promueve la adquisición de habilidades, y se constituyen espacios escolares en donde la integración se establecía en la convivencia de la escuela de siempre y la escuela de educación especial, o sea, los que tienen deficiencias con los normales, en un escenario normalizado, que conformaba a unos padres que por fin, podían llevar al mismo colegio a todos sus hijos, con la desestigmatización que esto suponía. Este proceso dejó en evidencia las diferencias y la posta que toma el modelo de inclusión, para seguir avanzando sobre el tema.

El significado etimológico de in clausere supone un límite que impone un adentro y un afuera, un nosotros y un otros, los que están enclaustrados, encerrados, delimitados, definidos por locación o por alguna taxonomía que genera el contraste con los que no están dentro o están fuera. La mayor posibilidad de inclusión se define entonces por no depender de lo que es, sino de lo que se hace con ello, en concordancia con Lévinas, en que el hacer es parte de una alerta y una atención permanentes ante la posible amenaza de la existencia del otro. La amenaza contempla cualquier reducción, por lo tanto,

15 La población marginal que surge y se acrecienta luego del profundo deterioro social. En las escuelas llamadas normales, el discurso de la diversidad ha tenido efectos concretos, aunque no siempre los de la promoción de la pluralidad subjetiva y social, sino más bien los de la tolerancia, cuando no los de la despreocupación o abandono hacia los secretos tradicionalmente estigmatizados y marginados.

16 En este punto es necesario rescatar que, a mediados del siglo XIX, se observan dos corrientes diferenciadas: la que sigue proporcionando un tratamiento médico-asistencial en los centros especializados y, otra, la que se apoya en la línea educativa iniciada por Itard, basada en una pedagogía curativa y rehabilitadora. A Itard se le atribuye un abordaje innovador para la época, distinto al médicopatológico, mediante su trabajo con el niño salvaje de Averyon (1800-1806), que plantea la posibilidad de aprendizaje de las personas deficientes. 
violencia de lo singular y de la comprensión de la existencia, considerando que entre el Yo y el Otro ${ }^{17}$, hay una asimetría irreductible.

Antes de continuar la búsqueda de referentes que propongan diferentes visiones complementarias que habiten y describan la "inclusión", nos detendremos sobre el concepto clave relacionado con el alter, el Otro, tomando la ética propuesta por Lévinas, ya que solo e inexorablemente la inclusión es en tanto la existencia de Otro que nos define y aparece como un "rostro", que no es solo una cara sino un nombre propio, que conforma un límite, proponiendo una paradoja insalvable -aporía-.

\section{El Otro, todo lo otro}

El interés sobre la ética levinasiana parte del análisis que provoca ese borde y contraste que nos supone el Otro, cómo y hasta dónde existe el vínculo. El desarrollo de Lévinas surge de la experiencia de los campos de internamiento y de Auschwitz, por lo que es una escritura sensible a cualquier indicio de totalitarismo. "La ética como sustitución con otro -donación sin reserva- rompe la unidad de la percepción trascendental, condición de todo ser" (Lévinas, 1975, p. 263).

Coincidiendo con Mèlich, en el que el totalitarismo supone adoctrinamiento y disciplinamiento, destacando que el mal

El desarrollo de Lévinas

surge de la experiencia de los

campos de internamiento y de

Auschwitz, por lo que es una

escritura sensible a cualquier

indicio de totalitarismo siempre es posible en tanto que no haya educación, invita a una primera cuestión que se debe atender: el mal en tensión a la cultura como su contraparte. Quizás un oscuro legado del pensamiento hegemónico propuesto por Occidente donde cultura, progreso, orden y bienestar parecen sinónimos. La ética propuesta es la de la responsabilidad, la de la no indiferencia de las diferencias que constituyen un Yo, un Mismo y un Otro. "La educación se sitúa contra la totalidad, contra el ser, porque el ser es el mal, la barbarie" (Mèlich, 1995, p. 146).

De esta relación podemos pensar: ¿qué se espera de ese Otro?, nada. ¿Cómo nos presentamos ante él? Una habilitación total, un servidor. "Es el 'heme aquí' dicho al prójimo al que me entrego y en el que anuncio la paz, es decir, mi responsabilidad ${ }^{18}$ para con Otro" (Lévinas, 1975, pp. 262-263). ¿Cuál es el estado del otro? Sin duda ajeno y diferente, pero desvalido e indigente, que obliga a la atención y al socorro, por lo que se desliza la necesidad imperante de una ética del Otro como filosofía primera, por ser una responsabilidad infinita e indelegable con el Otro -por delante inclusive de la ontología- que excede la rama homónima en la filosofía, y en esta operación se relega la subjetividad acunada en la mismidad, como responsabilidad esencial. El acontecimien-

17 Las mayúsculas pertenecen a los textos originales.

18 'Mi responsabilidad para con el Otro supone un volteamiento tal más que por un cambio de estatuto de 'mi', por un cambio de tiempo y quizás por el cambio de lenguaje" (Blanchot, 1990, p. 28). Por lo que se considera una relación asimétrica en historia y tiempo, en la que Blanchot destaca la dimensión que Lévinas le otorga más allá de la moral política. 
to es sin duda, la aparición del Otro, la trascendencia imperante que obliga una salida del Sí Mismo. Exterioridad hacia el rostro del Otro. ¿Qué es el Otro? El infinito que está afuera del todo, porque afuera está lo desconocido.

Cara a cara, de ahí surge la socialidad, importancia del porqué pensar la inclusión con un respaldo del pensamiento levinasiano, fuera de una moral subjetiva, ya que no puedo exigir al Otro, lo que me exijo a mí mismo. El ejercicio de la moral sin ese Otro, termina suprimiendo al sujeto, subordinándolo al todo, negándole diferencias y particularidades. $Y$ de nuevo la responsabilidad en la que no hay dimisión po-

El ejercicio de la moral sin ese

Otro, termina suprimiendo

al sujeto, subordinándolo al

todo, negándole diferencias y

particularidades sible: relación con, sin representación, sin intencionalidad y sin espera de reciprocidad.

El conocimiento no busca reducir: lo que se quiere es saber de ese Otro, respetando y reconociendo su libertad. La metafísica propone si es trascendencia en tanto que el Mismo es cuestionado por el Otro, en contraste con la ontología que retorna "lo Otro" a ese Mismo.

Un aprehender, quitándole la alteridad para comprenderlo, apresarlo: "no es una relación con lo Otro como tal, sino la reducción de lo Otro al Mismo" (Lévinas, 1977, p. 69) y ese "yo pienso" se transforma en "yo puedo", impulsando una universalidad impersonal en la que no hay presencia de humanidad. El poder está ligado a la propaganda, como se comprende en el totalitarismo. La metafísica como exterioridad absoluta, ya que es el más allá sin retorno, la extranjería.

El Otro metafísico es alteridad anterior a toda iniciativa, no es conceptualización y, por tanto, no es analogía, no es reflejo ni proyección, ni objetivación de mi imagen. "El otro es el huérfano, la viuda y el extranjero y a la vez, el Altísimo ante el que me siento indigno" (Lévinas, 1977, p. 37).

"La remisión del Otro es despertar, despertar en la proximidad, que es responsabilidad para con el prójimo, hasta la sustitución con él” (Lévinas, 1975, p. 255), no es el Mismo y no lo limita, ya que lo conforma. La alteridad es una heterogeneidad radical de lo Otro, un "Ser Mismo" absoluto, identidad por excelencia, el original de la identificación, y su poder se expresa al habitar "en lo de Sí" en libertad. Se plantea una alteridad que "no negará las angustias de la subjetividad al colocarse en perspectiva" (Lévinas, 1977, p. 29), ya sea de la metafísica o de la ontología.

El encuentro en la diferencia "no importa cuál sea la extensión de mi dominación y de su sumisión, no lo poseo" ya que, si hay sumisión, hay negación, por lo que no lo comprendo en cuanto a su historia, sus hábitos. La negación más absoluta es la muerte, puesto que "estar en relación con otro cara a cara, es no poder matar" (Lévinas, 1951, p. 18).

La relación descripta supone intimidad o de otra manera, el olvido del Ser, que busca comprensión y admite curiosidad, simpatía y amor: "le he hablado, es decir, he olvidado el ser universal que ella encarna para atenerme al ente particular que es" (Lévinas, 1951, p. 16); el vínculo no se reduce a la representación sino a su invocación, que se nombra y se llama al mismo tiempo: rostro como audición y como palabra en relación lingüística, "no contemplo, converso". Aparece el "darse", que es una exposición al concepto, y de 
significar a partir de lo que no se es. Dar sensiblemente para el Otro, cuánto nos dice en la educación. De-poner el "reino de la identidad", irremplazable responsabilidad que deviene en escisión del sujeto: "yo responsable no termino de vaciarme de mí mismo" (Lévinas, 1975, p. 260) para el Otro.

En cuanto a la diferencia, esta se instala a partir del lenguaje que reconoce dos términos separados, relaciona la ruptura de género -mayor extensión que incluye una menor que tiene que ver con la especie-, pero a la vez esa palabra que logra decir, nombrar, identificar al Otro, también lo contiene, pero no entra en la esfera del Mismo. La relación que se suscita no es violenta, es ética.

\section{Sobre el ejercicio responsable de la construcción del ethos}

Siguiendo a González Ocampo, estamos en los límites de lo que supusieron cambios retóricos. El entramado relacional es complejo ya que identidades, culturas, opciones sexuales deben ser registrados en una operación que implique visualización y legitimación, lo que supondrá una coherencia discursiva que atravie-

Las reflexiones de Lévinas dan
luz a la profundidad del vínculo
y la violencia que supone la
reducción a la totalidad, lo
que implica un arrasamiento
de la diversidad hacia la
homogeneidad
se las instituciones educativas, la consideración de sacar a la institución de una función que cada vez se acentúe más como mediadora de conflictos sociales y escolares y de ausencias o fracturas del entramado de sostén organizacional manifiesto. Este autor señala que las políticas públicas deben recuperar el sentido ético que colabore con la gestación de un pensamiento alternativo de la región. Sin ánimos reductivos, la inclusión debe suponerse en tanto que inclusión simbólica. Como disparador tomamos a Torrealba y Elichiry (2017, p. 292), quienes indican: "Pensamos las experiencias como actos instituyentes en el sentido de lo político, para dar cuenta de cómo lo nuevo entra en la historia: lo que caracteriza el acto instituyente es que [...] no es una creación que viene de la nada [...] es una creación que exige las tramas simbólicas, las constelaciones históricas, las herencias (Alemán, 2016, p. 50)".

Desde esa trama, se puede dar el sentido de novedad que abre a la posibilidad de articular hacia perspectivas situacionales, relacionales y sentidos construidos. Al centrar la visión en un Otro, se despliegan dimensiones de exterioridad, infinito, autonomía y heteronomía, subjetividad-intersubjetividad, respeto, dignidad y responsabilidad como parte de la esencia del hombre con y para el Otro. "[...] entrar en la relación de alteridad exige atravesar fronteras filosóficas, antropológicas, epistemológicas, éticas y estéticas" (Magendzo, 2006, p. 15).

Las reflexiones de Lévinas dan luz a la profundidad del vínculo y la violencia que supone la reducción a la totalidad, lo que implica un arrasamiento de la diversidad hacia la homogeneidad. Esta responsabilidad no objetiva ni tematiza. Según Magendzo, "Asumir la diversidad como relación significa, por de pronto, aceptar la inter y multiculturalidad como un nuevo paradigma de organización social" (2006, p. 12), como búsqueda de 
identidades y asociaciones, conformando una ética inclusiva, con el horizonte de que si hay un espacio de inclusión, habrá excluidos como una problemática que sigue siendo irresoluble, pero contemplada desde la atención al Otro como ruptura de la discriminación e incluso, de los que no tienen participación ni voz, como los casos de la discapacidad funcional y la discapacidad cognitiva. En el artículo, cita a Estévez en relación a la globalización con la interculturalidad y la comunicación, pero ¿qué hay de los que no pueden ejercer con libertad y autonomía la comunicación? Y con ello, ¿qué sucede en la educación inclusiva con los que no pueden expresarse por sí mismos y quedan subordinados a sus equipos terapéuticos y pedagógicos? ¿Qué hay más allá de lo que se instituye como hegemónico, incluso en el paradigma de la inclusión?

\section{Conclusiones}

1. La educación supone una revolución del Sí Mismo y su relación con el Otro y la exclusión es una decisión política.

[...] el hecho real de que exista una disminución de las capacidades cognitivas no significa que se carezcan absolutamente de ellas tanto como para llegar a "domesticar su conducta" hacia la manera más cómoda, como nos resulta "incluirlos o excluirlos" de nuestra super sociedad de la información. (Marchant Fernández, 2009, p. 41)

2. La bioética ${ }^{19}$ nos expone derechos que fueron y son vulnerados, allanando los marcos legales que amparan a las personas con discapacidad, los derechos del niño, los derechos a la educación, a la salud y a la vida autónoma, quedando escasos a la hora de considerar el respeto, dignidad, integridad, privacidad, confidencialidad, igualdad, equidad, no estigmatización y aceptación. La bioética se encuentra en una transformación en la que la impronta médica, que fue su punto de partida y conforma en parte su objeto, tiene que desplegar fundamentos para la construcción política desde una mirada diversa y multidisciplinar, colaborando con las epistemologías propias de Latinoamérica.

3. Bioética y una ética inclusiva para la educación: un punto de encuentro en que se refuercen sentidos. El proceso que se ha dado en la educación es coyuntural a los sentidos históricos, y ha sido expulsiva. Confrontemos dos hechos. Por un lado, los estándares que determinan la discapacidad, y por otro, la necesidad de la educación de complacer al mercado laboral y elevar sus propuestas a las exigencias tecnológicas de la sociedad.

4. El saber médico con poder creciente instala el concepto de inteligencia, construyendo formas de medición y test de inteligencia. Será entonces necesario tener institu-

19 Nos referimos a Declaración universal sobre Bioética y Derechos Humanos, de octubre del 2005. 
ciones que alberguen a los niños que no alcancen la media de inteligencia aceptable para la educación regular. Son los inicios de la educación especial. Este devenir típico de la ciencia ${ }^{20}$ no tendría que interferir en la persona como sujeto de derechos que, entre otros, suponen la igualdad ante la educación. Esta ilusión vivida por el colectivo de discapacidad ha sido erosionada, produciendo una desmoralización que tiene un impacto familiar cuando esta diversidad se hace presente. No se termina de dar respuesta o son insuficientes las dadas, ante la urgencia y las necesidades, y ante la exclusión o las disposiciones de las políticas educativas.

5. La desmoralización, como una problemática que supone el avasallamiento de valores éticos, en los que la responsabilidad o respuesta del Otro es arrancada. Según el análisis de Rueda Castro y Miranda (2002, p. 3):

\begin{abstract}
La persona desmoralizada (no es lo mismo que sin moral), al perder la iniciativa por satisfacer sus necesidades sociales y ejercer roles comunitarios, pierde al mismo tiempo las características que se le confieren como individuo de una especie que posee dignidad o, en otras palabras, que se encuentra capacitado para ejercer sus derechos y deberes que lo integran a un sistema organizado de usos sociales.
\end{abstract}

6. El proceso de merma de la dignidad personal ante la falta de responsabilidad de los diferentes actores reproductores, en parte de modelos discapacitantes que objetivan, identifican en demasía (discriminación positiva) o invisibilizan ambas prácticas estigmatizantes, se exacerban en espacios escolares. La discapacidad intelectual, como diversidad funcional, interpela profundamente las prácticas docentes, metodologías, espacios, dinámicas escolares, y herramientas didácticas con ese Otro. La responsabilidad ante esto y la construcción de una moral capacitante y valorativa, que solo una ética inclusiva como política de los Estados puede cobijar y custodiar, dista de las experiencias recogidas de los ámbitos escolares de educación especial.

7. La educación inclusiva para "todos" solo será plena y posible en un marco simbólico ético profundo que deberá impactar en la formación docente, elevándolo como un actor esencial en la conquista del modelo social, con todo lo que este implica. Si su observación es inclusiva, su praxis y ethos personal estarán en consonancia.

8. Acoger al Otro, abriéndose a su identidad. Salir al encuentro. La alteridad es una construcción heterogénea y radical de lo Otro, que es un "Sí Mismo" absoluto, por lo tanto, es identidad por excelencia, original en la identificación y su poder se expresa al habitar en libertad y autonomía, en donde el individuo habite su espacio común de con-vivencia y de un hacer plural compartido, comunitario con reglas que respondan al cuestionamiento de esas múltiples singularidades como una tarea que surge desde, por y para el prójimo pero como expresión solidaria y responsable, irreprimible

20 "Aproximadamente cada una década, la Asociación Americana de Retraso Mental (AAMR) elabora una nueva definición que es aceptada ampliamente por la comunidad científica (a excepción de unos pocos) y adoptada por educadores del área, más bien como una 'doctrina' que como una teoría refutable" (Marchant Fernández, 2009, p. 32), posición que demuestra la variabilidad de las definiciones y su impacto categórico en la educación. 
e irreducible ni en sus tiempos ni sentidos morales o estéticos; en construcción de un "nosotros" tangible sin ficciones instaladas que conforman desalojos violentos del espacio común que puede adoptar una forma directa y explícita o políticamente correcta del "hacemos cómo" para nada.

9. La discapacidad intelectual nos obliga a una mirada holística (Schalok, 2018), en una conversación cercana en la que el diagnóstico no impida ver su rostro y el paradigma del déficit no termine desdibujándolo. Y desde este punto de partida, entonces, pensar desde las cualidades que surgen de los usuarios, cómo construimos una educación inclusiva desde una ética del respeto y la responsabilidad por el Otro y su integridad, un espacio de encuentro como acto instituyente. En convivencia, construir un nosotros. "Nuestra libertad, la irreductibilidad que anida en cada uno de nosotros, depende hoy de que sepamos conquistar, juntos, la vulnerabilidad de nuestros cuerpos expuestos, la precariedad generalizada de nuestras vidas" (Garcés, 2013, p. 50).

\section{Referencias}

Ainscow, M. (2003). Desarrollo de sistemas educativos inclusivos. Recuperado de https://sid.usal.es/idocs/ F8/FD06565/mel_ainscow.pdf

Arnaiz Berrezo, P. (2009). Educación inclusiva. Artículo presentado en el I Congreso Nacional de Buenas Prácticas en Educación, Diversidad y Empleo. Murcia: Universidad de Murcia.

Blanchot, M. (1990). La escritura del desastre. Caracas: Monte Ávila.

Braidotti, R. (2005). Metamorfosis: Hacia una teoría materialista del devenir. España: Akal Ediciones.

Enríquez Canto, Y. (2018). Estatus personal en la discapacidad intelectual: considerando las capacidades cognitivas. Revista Latinoamericana de Bioética, 18(35-2), 226-241. DOI: https://doi.org/10.18359/ rlbi.3137

Foucault, M. (2000). Defender la sociedad. Curso en el Collège de France (1975-1976). Buenos Aires: FCE.

Garcés, M. (2013). Un mundo común. Barcelona: Edicions Bellaterra.

Garcés, M. (2011). ¿Qué podemos hacer? 0 sobre las intimidades de la crítica. En O. Cornago (ed.), A veces me pregunto por qué sigo bailando (pp. 393-408). Madrid: Contintametienes.

Geertz, C. (2003). La interpretación de las culturas. Barcelona: Editorial Gedisa.

Goffman, E. (2006). Estigma. Buenos Aires: Amorrortu.

González Ocampo, A. (2016). ¿Educación inclusiva o educación para todos?: La necesidad de proponer un enfoque reconstruccionista sobre sus fundamentos vigentes. Revista de Psicopedagogía REPSi, 140, 1-15.

Lévinas, E. (1951). ¿Es fundamental la ontología? Entre Nosotros, Ensayos para pensar en Otro, 1, 13-23. Recuperado de https://www.filosofia.mx/es-fundamental-la-ontologia-de-emmanuel-levinas/ 
Lévinas, E. (1975). Dios y la filosofía. Nouveau Commerce, 1(Grand in-8). Recuperado de https://www. google. $\mathrm{com} /$ search?client=avg\&q=Dios+y+la+filosofia+levinas

Lévinas, E. (1977). Totalidad e infinito: Ensayo sobre la exterioridad. Salamanca: Ediciones Sígueme.

Magendzo, A. (2006). El Ser del Otro: Un sustento ético-político para la educación. Polis. Revista Latinoamericana, 15. Recuperado de http://journals.openedition.org/polis/4897

Marchant Fernández, C. (2009). La voz del alumnado de la educación especial proveniente de la educación ordinaria. Historias de vida y exclusión educativa en Barcelona (Tesis Doctoral). Universitat de Barcelona, Barcelona. Recuperado de http://diposit.ub.edu/dspace/bitstream/2445/41497/1/01.CMF_TESIS.pdf

Martínez, Ó., Planella, J., \& E-libro, C. (2010). Alterando la discapacidad: Manifiesto a favor de las personas. Barcelona: Editorial UOC

Mèlich, J. C. (1995). La maldat de l'ésser. La filosofia de l'educació d'Emmanuel Levinas. Enrahonar. An international journal of theoretical and practical reason, 24(0), 145-154. DOI: https://doi.org/10.5565/rev/ enrahonar.611

Oliver, Michael J. (1996). ¿Una sociología de la discapacidad o una sociología discapacitada? En Len Barton (ed.), Discapacidad y sociedad. Madrid: Morata.

Palacios, A. (2008). El modelo social de discapacidad orígenes, caracterización y plasmación en la Convención Internacional sobre los Derecho de las Personas con Discapacidad. Madrid: Cinca.

Quiroga, P. (2010). La evolución de la atención a la diversidad del alumnado de educación primaria a lo largo de la historia. Innovación y experiencias educativas. Recuperado de http://www.csicsif.es/andalucia/ modules/mod_ense/revista/pdf/Numero_15/t_MIGUEL_TORRALBO_1.pdf

Rueda Castro, L., y Miranda Zúñiga, O. (2002). Principales dilemas Bioéticos en las personas con discapacidad prolongada. Acta bioethica, 8(1). DOI: https://doi.org/10.4067/S1726-569X2002000100012

Schalock, R. (2018). Seis ideas que están cambiando el campo de las discapacidades intelectuales y del desarrollo en todo el mundo. Siglo Cero. Revista Española sobre Discapacidad Intelectual, 49(1), 7-19. DOI: https://doi.org/10.14201/scero2018491719

Torrealba, M., y Sánchez, A. (2017). Inclusión educativa: tramas de experiencias de lo común que interpelan las tradiciones escolares. Construyendo puentes entre la perspectiva psicológica situacional y el psicoanálisis. IX Congreso Internacional de Investigación y Práctica Profesional en Psicología XXIV MERCOSUR. Facultad de Psicología - Universidad de Buenos Aires, Buenos Aires.

Yarza de los Ríos, V. (2013). Hacer sitio al que llega: Pedagogía, educación especial y formación. 36-43. Recuperado de https://www.hum.unrc.edu.ar/publicaciones/contextos/articulos/vol14/pdfs/04-yarza.pdf 